\title{
Post-traumatic stress symptoms among former child soldiers in Sierra Leone: follow-up study ${ }^{\dagger}$
}

Theresa S. Betancourt, Elizabeth A. Newnham, Ryan McBain and Robert T. Brennan

\section{Background}

Former child soldiers are at risk of developing post-traumatic stress disorder (PTSD); however, the trajectory of symptoms has yet to be examined.

\section{Aims}

The risk and protective factors associated with PTSD symptom change among former child soldiers in Sierra Leone were investigated.

\section{Method}

Data from 243 former child soldiers (mean age 16.6 years, $30 \%$ female) were analysed.

\section{Results}

Self-reported rates of possible PTSD using standard cut-off points declined from $32 \%$ to $16 \% 4$ years later $(P<0.05)$.

Symptoms of PTSD at baseline were significantly associated with war experiences $(P<0.01)$ and post-conflict family abuse $(P<0.001)$. Reliable improvement in symptoms was reported by $30 \%$. In growth models examining symptom change, worsening of symptoms was associated with death of a parent $(P<0.05)$ and post-conflict stigma $(P<0.001)$. Protective effects were observed for increases in family acceptance $(P<0.001)$.

\section{Conclusions}

The findings indicated improvement in PTSD symptoms among former child soldiers despite limited access to care. Family and community support played a vital part in promoting psychological adjustment.

\section{Declaration of interest}

None.
The nature of modern warfare is changing and civilians have increasingly become caught in the violence. As a result, modern wars have witnessed a sizeable number of children involved with armed forces and armed groups (referred to here as 'child soldiers'). These young people assume a variety of roles, including acting as spies, porters and front-line soldiers, and are often involved in the perpetration of violence towards others as well as being subjected to repeated physical, sexual and emotional violence. Former child soldiers are at risk of developing symptoms of post-traumatic stress disorder (PTSD) ${ }^{1,2}$ However, despite the high rates of PTSD documented in this population, ${ }^{2,3}$ there have been few assessments of the longitudinal course of symptoms in both male and female child soldiers. ${ }^{4}$ Within a cohort of 39 boys formerly child soldiers in Mozambique, reports of post-traumatic distress reduced over time, coupled with an increase in avoidance behaviours. ${ }^{5}$ Similarly, intervention studies have demonstrated responsiveness to psychological treatments among former child soldiers exhibiting post-traumatic stress and depression symptoms. ${ }^{6-8}$ A complex interplay of risk and protective factors is likely to influence the psychological adjustment of former child soldiers. Most experience chronic exposure to violence and repeated victimisation, yet differ with regard to the frequency, duration and severity of their war-related violence exposures. ${ }^{1}$

The post-conflict environment is also important in determining the course of psychopathological disorder. War-affected children, and former child soldiers in particular, are vulnerable to economic insecurity and interpersonal hardship. ${ }^{9}$ Prior research indicates that former child soldiers often face stigma in the community, ${ }^{10}$ domestic violence, ${ }^{11}$ and numerous daily stressors or hardships, ${ }^{1,9}$ on release or escape. However, former child soldiers may differ with regard to the post-conflict opportunities they encounter, particularly in terms of access to school, family and community supports, and economic circumstances. ${ }^{12}$ Despite great interest in the risks of PTSD among former child soldiers, no empirical work

\footnotetext{
†See editorial, pp. 165-167, this issue.
}

has explicitly investigated how individual, family and community risk and protective processes influence post-traumatic stress symptoms over time. ${ }^{4}$ We predicted that post-traumatic stress symptoms in this sample would persist over time, and would be associated with severe war violence and post-conflict hardships, whereas protective factors such as family support and community acceptance would be associated with a decrease in symptoms.

\section{Method}

We used an analytic sample of former child soldiers from the Longitudinal Study of War Affected Youth in Sierra Leone, ${ }^{1}$ a prospective cohort study of 529 youths $(74 \%$ of whom were former child soldiers) monitored over a 6-year period. Baseline data collection occurred in $2002\left(T_{1}\right)$, with subsequent data collection in $2004\left(T_{2}\right)$ and $2008\left(T_{3}\right)$. Two cohorts of participants who reported involvement in fighting forces and who had data available at $T_{2}$ and $T_{3}$ were included in this sample. The first were a subset of former child soldiers $(n=127)$ identified according to International Rescue Committee (IRC) registries, who had received services through an interim care centre run by a nongovernmental organisation (NGO) during the most active period of demobilisation (June 2001 to February 2002) serving five districts of Sierra Leone (Bo, Kenema, Kono, Moyamba and Pujehun). The second portion of the sample consisted of selfreintegrated child soldiers $(n=116)$ identified from outreach lists established by an NGO in the Bombali district of Sierra Leone. The analytic sample comprised former child soldiers $(n=243$; mean age at baseline 16.58 years, s.d. $=2.62 ; 30 \%$ female). Thirty-five participants were lost to follow-up between $T_{2}$ and $T_{3}$. Their PTSD scores at $T_{2}$ were not significantly different from the rest of the sample $(t(275)=1.12, P=0.27)$. Attrition was largely due to participants' relocation during the study period.

Data for all participants were collected through face-to-face interviews conducted by Sierra Leonean research assistants trained 
and monitored by the study principal investigators and IRC staff. Symptoms of PTSD were assessed in $2004\left(T_{2}\right)$ and $2008\left(T_{3}\right)$; thus, the current sample is composed of participants for whom data were available at both time points. All instructions and consents/assents were read aloud in the local language of Krio separately to caregivers and the young people. Local social workers provided follow-up and triage for any participants who required further support for risk of harm situations or suicidality (about $5 \%$ of the sample). All research protocols and procedures were approved by the institutional review boards of Boston University Medical School/Boston Medical Center and the Harvard School of Public Health.

\section{Measures}

Qualitative data collection and in-depth consultation with Sierra Leonean staff and community members were used to select and adapt all measures. ${ }^{12}$ Measures were forward- and back-translated according to a standardised protocol. ${ }^{13}$

\section{War experiences}

The Childhood War Trauma Questionnaire (CWTQ) was adapted by our research team to capture war-related exposures typical of the experiences of young people during Sierra Leone's conflict. ${ }^{14}$ War experiences were dichotomously coded. Age of abduction and time with the fighting forces were derived from questions added to the CWTQ. Three forms of violence exposure previously demonstrated to have potent effects on mental health outcomes among war-affected Sierra Leonean youth were included in the growth models: death of a parent due to war, being a victim of rape and perpetration of violence by injuring or killing another person. ${ }^{1,14}$ Participants completing the CWTQ were asked to identify the traumatic experience that currently bothered them the most and to answer the PTSD symptom questions with reference to that event.

\section{Post-traumatic stress disorder}

The nine-item short form of the UCLA Post-Traumatic Stress Disorder Reaction Index (PTSD-RI) was administered, ${ }^{15}$ with an additional three items from the original long form. The 12-item PTSD-RI had good internal consistency in this sample (Cronbach's $\alpha=0.89$ at $T_{2}, \alpha=0.83$ at $T_{3}$ ). Frequency of symptoms over the past month was reported on a three-point scale ('never', 'sometimes' and 'often'). This scale has demonstrated strong psychometric properties in studies of war-exposed youth. ${ }^{16}$ Cut-off points were determined in two steps. First, we identified the point recommended by the authors for the nine-item scale, ${ }^{17}$ from which participants scoring 17 or above were designated as meeting clinical criteria for 'possible PTSD'. Second, responses to individual items were related to DSM-IV-TR criteria such that individuals who reported 'often' one or more times for at least one item in each of three DSM-IV-TR categories - intrusion, avoidance and arousal met criteria for possible PTSD. ${ }^{18}$ Combining these approaches maximises specificity and thus provides a lower bound for the classification of individuals likely to have PTSD.

To investigate the validity of the use of the PTSD-RI in Sierra Leone we conducted preliminary analyses comparing it with the Oxford Measure of Psychosocial Adjustment, which was developed and validated in Sierra Leone. ${ }^{19}$ We found that PTSD symptom scores were strongly correlated with the anxiety subscale of the Oxford measure ( $r=0.61$ at baseline, $r=0.53$ at follow-up), providing evidence of concurrent validity. The PTSD symptom scores were only weakly associated with confidence and pro-social subscales of the Oxford measure (absolute values of $r$ were all less than 0.1 ), providing evidence of discriminant validity.

\section{Family acceptance}

A measure of family acceptance was drawn from our previous qualitative work and consultations with local staff. ${ }^{20}$ The six-item measure assessed the way former child soldiers perceived acceptance and respectful treatment within their family, scored as 'not true', 'sometimes true' or 'very true.' This measure exhibited good internal consistency (Cronbach's $\alpha=0.90$ at $T_{2}, \alpha=0.86$ at $T_{3}$ ). ${ }^{1,12}$

\section{Family abuse and neglect}

The Family Relations Scale was adapted from the Childhood Trauma Questionnaire, ${ }^{21}$ and included items that assess five types of maltreatment: physical, sexual and emotional abuse, and physical and emotional neglect. The scale demonstrated good internal consistency (Cronbach's $\alpha=0.70$ at $T_{3}$ ).

\section{Stigma}

The Everyday Discrimination Scale captures negative community interactions such as differential treatment, threats or abuse due to discrimination. ${ }^{22}$ For each of the nine items, possible responses were 'never' (scored 0), 'sometimes' (1) and 'always' (2). For each item endorsed as 'sometimes' or 'always' the interviewer probed as to the reason for the discrimination. Potential reasons included disability, gender, age, religion, poverty, level of education, tribe or previous involvement as child soldier, as well as an open-ended option for other reasons. The analysis reported here used only items related to discrimination due to being a former child soldier. The scale demonstrated good internal consistency in this setting (Cronbach's $\alpha=0.76$ at $T_{2}, \alpha=0.91$ at $T_{3}$ ). ${ }^{1,10}$

\section{Participation in school}

The young people were asked whether they were currently attending school (scored dichotomously).

\section{Services received}

Participants were asked about a range of services received following the war. Among these was a question as to whether anyone in their household had received formal or informal services or other interventions for emotional or psychological problems within the past year. Services were reported at the household level to reduce the influence of stigma in reporting and because services received by any member of the household have potential to affect the well-being of the participating child.

\section{Demographic characteristics}

A demographic inventory collected information on participants' gender, age and family socioeconomic resources at each time point, drawing from standard items on the United Nations Children's Fund (UNICEF) Multiple Indicator Cluster Survey. ${ }^{23}$ The measure of socioeconomic status was created to indicate an individual's access to food, housing and clothing relative to others in the community. The measure comprised four items and had good internal consistency (Cronbach's $\alpha=0.76$ at $T_{2}$ ). Other services were assessed by yes/no questions asking about services received for food items, non-food items and support to pay for school fees.

\section{Statistical analysis}

For continuous variables, means and standard deviations were calculated as descriptive measures, and for categorical data, descriptive statistics were calculated using frequencies and associated percentages. Rates of reliable change were calculated according to Jacobson \& Truax's criteria. ${ }^{24}$ A reliable change index enables examination of change at the individual level. ${ }^{25}$ To calculate this index, the participant's baseline score was subtracted from the 
follow-up score and divided by the standard error of difference for the measure; reliable change was achieved if the resulting score was greater than 1.96 .

Growth models were estimated to examine the relationship between risk and protective factors and symptoms of PTSD. To address concerns about modelling change with only two time points, the two-point growth models used in this analysis are derived from the three-point model developed by Raudenbush et $a l,{ }^{26}$ which used a two-level hierarchical linear model to fit a quadratic function using three time points by incorporating a measurement model to account for unreliability of the outcomes. ${ }^{27}$ Subsequently, Goldberg \& Smith employed a similar strategy to create a linear growth model with two time points. ${ }^{28,29}$ To create the measurement model, the 12 PTSD items were assigned to two parallel scales of six items each, matched on standard deviations and centred on zero. Each of the parallel outcome scales was then divided by the number of items. Because of the division of each of the subscales by the number of items, each of the coefficients may be interpreted in terms of a unit change in a single PTSD scale item (e.g. from 'sometimes' to 'often'). In these models the fixed portion of the intercept was constrained to be equal to zero (because of the centring of the subscale items on zero), whereas the random component was estimated - meaning that the individual estimates were free to vary around zero. For the slope, representing change over the two time points, both the fixed and random components were estimated. Predictors of the change in PTSD were divided into time-varying covariates (e.g. family acceptance), which were observed separately at $T_{2}$ and $T_{3}$ and varied directly with the outcome, and time-invariant predictors (e.g. parental death during the war), which had only one value across both time points and predict the steepness and direction of the slope. Predictors of the slope (coefficients) were interpreted as associated with a decrease in symptoms over time $\left(T_{2}\right.$ to $\left.T_{3}\right)$ if negative, or an increase in symptoms if positive.

Variables were entered into the growth models in three steps: the first included demographic characteristics and socioeconomic status. War exposures, including death of a parent due to war, were entered at the second step. The third step covered postconflict factors including family abuse and neglect, family acceptance and stigma. Stigma and family acceptance data were available at both time points and were thus entered as time-varying covariates. The inclusion of access to school and access to psychological services did not significantly improve model fit when tested within the final model, and were thus removed from that model. Further, to test whether a significant difference existed between the two cohorts (children from the interim care centres and those who were self-reintegrated), the care centre variable was tested in the growth model. The results revealed that being in the portion of the cohort drawn from care centre rosters was not a significant predictor of intercept or slope.

Missing data were addressed using multiple imputation (20 imputations). ${ }^{30}$ Overall, the level of missing data ranged from $0 \%$ to $1.5 \%$ (death of parent due to war). All statistical tests were two-sided and conducted at the $\alpha=0.05$ significance level. Growth modelling was performed using HLM version 7.0, ${ }^{31}$ multiple imputation analysis was conducted using Stata version 11.0/SE's multiple imputation suite (command MI) and descriptive analyses were conducted in SPSS version 18 on Windows.

\section{Results}

The main demographic characteristics of the sample are presented in Tables 1 and 2. The average age at abduction was 11.2 years, with participants reporting being held by the rebels for an average of 2.9 years. Most participants were in school at the time of the 2004 assessment $(80 \%)$. The interventions received did not differ by gender $(P=0.19-1.0)$. Significantly more young participants served by interim care centres reported household access to psychological services $(P=0.03)$ but there was no significant difference for other services examined.

\section{War exposures}

Although sexual assault was reported by both boys and girls (Table 2), significantly more girls in this sample reported rape and sexual assault compared with boys $(55 \%$ v. $6 \%, P<0.0001)$. More girls than boys in the sample had had a parent die owing to war $(40 \%$ v. $25 \%, P<0.05)$. The final war exposure included in growth models - involvement in the perpetration of violence - was also reported among both genders. In total, $36 \%$ endorsed having injured or killed someone: $38 \%$ of boys and $32 \%$ of girls $(P>0.05)$.

\section{PTSD}

Criteria for possible PTSD, using the nine-item cut-off point, ${ }^{17}$ was met in $32 \%(n=76)$ of the sample at baseline and in $16 \%$ $(n=38)$ at follow-up $(P<0.05)$. Using continuous scores at an individual level, reliable improvement over time was reported by $30 \%(n=72)$ of the sample, $65 \%(n=157)$ demonstrated no reliable change and $5 \%(n=13)$ reliably worsened in symptoms over time. Girls reported significantly higher PTSD scores at baseline than boys $(P<0.001)$, but there was no significant difference in PTSD scores between the genders at follow-up (Table 2).

In the growth model (Table 3), analyses of continuous scores indicated that higher average PTSD scores at baseline were associated with experience of rape during the war $(P<0.01)$, and injury or killing others $(P<0.01)$. Family abuse and neglect following the war $(P<0.001)$ were also significantly associated with higher average PTSD scores. Increasing symptoms of PTSD over time were significantly associated with death of a parent due to war $(P<0.05)$. In addition, community stigma positively covaried with PTSD scores, meaning that an increase in stigma from baseline to follow-up was associated with an increase in symptoms $(P<0.001)$; in fact, slightly more than a one unit change in stigma would offset half the negative slope in PTSD. Conversely, family acceptance inversely covaried with PTSD levels, such that an increase in family acceptance from baseline to follow-up was associated with a decrease in PTSD scores $(P<0.001)$. Accordingly, one standard deviation change in family acceptance would offset the negative slope in PTSD scores by more than half (net -0.079). Each step in progressive model construction - demographic characteristics, war exposures, postwar factors and time-varying covariates - represented a significant improvement in overall model fit. Final model fit statistics were equivalent to $R^{2}=0.44$ for intercept and $R^{2}=0.28$ for slope.

\section{Discussion}

Many former child soldiers reported post-traumatic stress symptoms in the years following war, but nearly a third experienced reliable improvement in these symptoms over time, despite limited access to care. An increase in symptoms was reported by a small proportion of participants and was associated with death of a parent and post-conflict stigma. These findings augment recent studies of war-affected youth that highlight the natural resiliency in this sample across a range of psychological outcomes. ${ }^{32-36}$ 


\begin{tabular}{|c|c|c|c|c|c|c|}
\hline & \multicolumn{2}{|c|}{ Full sample $(n=243)$} & \multirow{2}{*}{$\begin{array}{c}\text { Boys }(n=170) \\
\text { Mean (s.d.) }\end{array}$} & \multirow{2}{*}{$\begin{array}{l}\text { Girls }(n=73) \\
\text { Mean (s.d.) }\end{array}$} & \multirow[b]{2}{*}{$P$} & \multirow{2}{*}{$\begin{array}{l}\text { Number of } \\
\text { observations }\end{array}$} \\
\hline & Mean (s.d.) & Range & & & & \\
\hline \multicolumn{7}{|l|}{ Age, years } \\
\hline At baseline & $16.58(2.62)$ & $11-22$ & $16.76(2.64)$ & $16.18(2.52)$ & 0.113 & 243 \\
\hline At abduction & $11.19(3.05)$ & $2-18$ & $11.01(3.00)$ & $11.72(3.18)$ & 0.155 & 196 \\
\hline Time with armed forces, years & $2.95(2.33)$ & $<1-11$ & $3.33(2.18)$ & $1.88(2.43)$ & $<0.001$ & 203 \\
\hline SES score & $9.45(2.20)$ & $4-14$ & $9.57(2.22)$ & $9.15(2.15)$ & 0.170 & 242 \\
\hline \multicolumn{7}{|l|}{ PTSD score } \\
\hline At baseline & $14.68(8.35)$ & $0-34$ & $13.17(8.45)$ & $18.20(6.97)$ & $<0.001$ & 237 \\
\hline At follow-up & $10.90(7.06)$ & $0-30$ & $10.60(7.09)$ & $11.61(7.01)$ & 0.318 & 237 \\
\hline Family abuse and neglect score & $1.08(1.51)$ & $0-6$ & $1.18(1.55)$ & $0.85(1.38)$ & 0.115 & 24 \\
\hline \multicolumn{7}{|l|}{ Family acceptance score } \\
\hline At baseline & $10.67(2.58)$ & $0-12$ & $10.85(2.49)$ & $10.26(2.75)$ & 0.107 & 239 \\
\hline At follow-up & $10.27(2.73)$ & $0-12$ & $10.24(2.69)$ & $10.33(2.85)$ & 0.808 & 235 \\
\hline \multicolumn{7}{|l|}{ Child soldier stigma score } \\
\hline At baseline & $3.03(3.92)$ & $0-17$ & $2.45(3.62)$ & $4.38(4.28)$ & $<0.001$ & 242 \\
\hline At follow-up & $1.08(2.44)$ & $0-15$ & $1.18(2.55)$ & $0.86(2.13)$ & 0.359 & 243 \\
\hline
\end{tabular}

\begin{tabular}{|c|c|c|c|c|c|}
\hline & $\begin{array}{c}\text { Full sample }(n=243) \\
n(\%)\end{array}$ & $\begin{array}{c}\text { Boys }(n=170) \\
n(\%)\end{array}$ & $\begin{array}{c}\text { Girls }(n=73) \\
n(\%)\end{array}$ & $P$ & $\begin{array}{l}\text { Number of } \\
\text { observations }\end{array}$ \\
\hline $\begin{array}{l}\text { Research group } \\
\text { NGO-integrated } \\
\text { Self-reintegrated }\end{array}$ & $\begin{array}{l}127(52.3) \\
116(47.7)\end{array}$ & $\begin{array}{r}114(67.1) \\
56(32.9)\end{array}$ & $\begin{array}{l}13(17.8) \\
60(82.2)\end{array}$ & $<0.001$ & 243 \\
\hline $\begin{array}{l}\text { Religion } \\
\text { Christian } \\
\text { Muslim }\end{array}$ & $\begin{array}{l}113(46.5) \\
130(53.5)\end{array}$ & $\begin{array}{l}77(45.3) \\
93(54.7)\end{array}$ & $\begin{array}{l}36(49.3) \\
37(50.7)\end{array}$ & 0.565 & 243 \\
\hline $\begin{array}{l}\text { War exposures } \\
\text { Death of parent } \\
\text { Victim of rape } \\
\text { Killed or injured others }\end{array}$ & $\begin{array}{l}70(29.3) \\
50(20.6) \\
87(35.8)\end{array}$ & $\begin{array}{l}41(24.7) \\
10(5.9) \\
64(37.7)\end{array}$ & $\begin{array}{l}29(39.7) \\
40(54.8) \\
23(31.5)\end{array}$ & $\begin{array}{r}0.019 \\
<0.001 \\
0.360\end{array}$ & $\begin{array}{l}239 \\
243 \\
243\end{array}$ \\
\hline $\begin{array}{l}\text { PTSD } \\
\text { Met criteria at baseline } \\
\text { Met criteria at follow-up }\end{array}$ & $\begin{array}{l}76(32.1) \\
38(16.0)\end{array}$ & $\begin{array}{l}41(24.7) \\
26(15.7)\end{array}$ & $\begin{array}{l}35(49.3) \\
12(16.9)\end{array}$ & $\begin{array}{r}<0.001 \\
0.812 \\
\end{array}$ & $\begin{array}{l}237 \\
237\end{array}$ \\
\hline $\begin{array}{l}\text { Education } \\
\text { In school at baseline } \\
\text { In school at follow-up }\end{array}$ & $\begin{array}{l}191(80.3) \\
136(56.4)\end{array}$ & $\begin{array}{r}145(86.3) \\
99(58.6)\end{array}$ & $\begin{array}{l}46(65.7) \\
37(51.4)\end{array}$ & $\begin{array}{r}<0.001 \\
0.303 \\
\end{array}$ & $\begin{array}{l}238 \\
241\end{array}$ \\
\hline $\begin{array}{l}\text { Services received (past year) } \\
\text { Psychological services } \\
\text { Food items } \\
\text { Non-food items } \\
\text { School or vocational support }\end{array}$ & $\begin{aligned} & 15(6.4) \\
& 12(4.9) \\
& 5(2.1) \\
& 12(4.9)\end{aligned}$ & $\begin{array}{r}12(7.2) \\
9(5.3) \\
5(2.9) \\
6(3.5)\end{array}$ & $\begin{array}{l}3(4.3) \\
3(4.1) \\
0(0.0) \\
6(8.3)\end{array}$ & $\begin{array}{l}0.56 \\
1.00 \\
0.33 \\
0.19\end{array}$ & $\begin{array}{l}235 \\
242 \\
243 \\
241\end{array}$ \\
\hline
\end{tabular}

Consistent with other studies of former child soldiers, ${ }^{3,37}$ we found that exposure to 'toxic' war experiences had detrimental effects on baseline symptoms (2 years after the cessation of conflict). Surviving rape and perpetrating violence demonstrated a strong relationship with initial PTSD levels, perhaps owing to their intimate nature and intensity. However, a great deal of variability in PTSD outcomes over time also characterised the sample. We observed that, over time, family and community factors were important in predicting post-traumatic stress symptoms. In particular, family abuse and neglect were associated with increased symptoms, and death of a parent due to war was associated with worsening of symptoms. Family acceptance in the post-conflict period was significantly related to lower PTSD scores. These findings reflect the vital role of a child's social ecology in mental health recovery following war. ${ }^{32-34}$ For former child soldiers in particular the role of the family appears to be central in aiding recovery. Research in similar settings has depicted the importance of a stable post-conflict family environment through levels of family abuse and neglect, domestic violence, family conflict and access to education, resources and opportunities. ${ }^{11,12,32,35}$ Two community factors also played a part in mental health recovery: stigma and perceived discrimination due to former association with fighting forces were significantly associated with worsening of post-traumatic stress symptoms over time, which is noteworthy for future research investigating the reintegration of former child soldiers. ${ }^{10}$

The findings highlight a striking gender difference in rates of improvement. Although girls reported significantly higher symptoms at $T_{2}$, there was no difference in symptoms between the genders at $T_{3}$. Previous examinations of mental health outcomes analysed according to gender have demonstrated higher levels of distress among female war- and disaster-affected children. ${ }^{38-40}$ However, there is also evidence of increased vulnerability for boys who have lost caregivers or experienced 
Table 3 Two-point growth model of risk and protective factors associated with post-traumatic stress ${ }^{a}$

\begin{tabular}{|c|c|c|c|c|c|c|}
\hline & \multicolumn{2}{|c|}{ Model 1} & \multicolumn{2}{|c|}{ Model 2} & \multicolumn{2}{|c|}{ Model 3} \\
\hline & Intercept (s.e.) & Slope (s.e.) & Intercept (s.e.) & Slope (s.e.) & Intercept (s.e.) & Slope (s.e.) \\
\hline \multicolumn{7}{|l|}{ Demographic factors } \\
\hline Intercept & & $-0.73(0.13)^{\star * *}$ & & $-0.72(0.13)^{\star \star *}$ & & $-0.51(0.13)^{\star \star *}$ \\
\hline Age & $0.00(0.03)$ & $-0.08(0.04)^{\mathrm{b}}$ & $-0.02(0.02)$ & $-0.07(0.04)$ & $-0.01(0.02)$ & $-0.03(0.04)$ \\
\hline Gender & $0.54(0.17)^{\star *}$ & $-0.66(0.30)^{\star}$ & $0.30(0.18)^{b}$ & $-0.56(0.34)$ & $0.29(0.15)^{b}$ & $0.03(0.32)$ \\
\hline SES & $-0.02(0.04)$ & $0.06(0.07)$ & $0.02(0.03)$ & $0.06(0.07)$ & $-0.02(0.03)$ & $0.03(0.06)$ \\
\hline \multicolumn{7}{|l|}{ War exposures } \\
\hline Death of parent & & & $0.42(0.17)^{\star}$ & $0.46(0.30)^{*}$ & $0.24(0.15)$ & $0.57(0.27)^{\star}$ \\
\hline Victim of rape & & & $0.60(0.20)^{* *}$ & $-0.42(0.40)$ & $0.50(0.18)^{\star *}$ & $-0.61(0.34)^{b}$ \\
\hline Killed or injured others & & & $0.96(0.16)^{* * *}$ & $-0.49(0.29)^{b}$ & $0.42(0.14)^{* *}$ & $-0.30(0.27)$ \\
\hline \multicolumn{7}{|l|}{ Post-war factors } \\
\hline Family abuse & & & & & $0.22(0.05)^{* * *}$ & $0.11(0.08)$ \\
\hline \multicolumn{7}{|l|}{ Time-varying covariates } \\
\hline Family acceptance & & & & & $-0.11(0.02)^{\star * *}$ & \\
\hline Child soldier stigma & & & & & $0.23(0.03)^{\star * *}$ & \\
\hline$R^{2}$ & 0.04 & 0.04 & 0.24 & 0.07 & 0.44 & 0.28 \\
\hline \multicolumn{7}{|c|}{$\begin{array}{l}\text { s.e., robust standard errors; SES, socioeconomic status. } \\
\text { a. Coefficient }(\beta) \text { of } \pm 1 \text { represents a one-unit increase/decrease on each individual item of the UCLA Post-Traumatic Stress Disorder Reaction Index (PTSD-RI). } \\
\text { b. } P<0.10 \text {. } \\
{ }^{*} P<0.05,{ }^{* *} P<0.01,{ }^{* *} P<0.001 \text {. }\end{array}$} \\
\hline
\end{tabular}

rape. ${ }^{40}$ In addition, gender has been shown to be a differentiating factor in coping among war-affected populations, ${ }^{41}$ and the current findings suggest that girls demonstrated higher rates of improvement across the 4 -year follow-up period. It is also noteworthy that 2 years after the cessation of combat $\left(T_{2}\right)$ two-thirds of the sample did not meet a standard cut-off score for possible PTSD despite reporting exposure to a range of severe war traumas. This result underscores the fact that, in working with such populations, more refined tools for screening and assessment are needed to identify those who have truly persistent distress and impairment and few protective resources, rather than simply relying on categorical labels such as 'former child soldier' to determine access to services.

Ultimately, these young people present with a great deal of comorbidity; reliable improvement in post-traumatic stress symptoms does not necessarily mean improvement in other symptoms. Examination of such patterns is an important area for future research. Models of care should work to build on naturally occurring protective processes in war-affected families and communities. For instance, the finding that post-traumatic stress symptoms were lower among young people in the presence of a high degree of family support is promising and has important intervention implications. Psychological treatments narrowly focused on past traumas alone may not be appropriate for helping these young people navigate the stressors they face in the post-conflict environment. Our findings suggest that the impact of interventions may be greater if they include familybased elements. Such naturally occurring protective processes bear consideration in future longitudinal studies and can be critical to ensuring the success of interventions.

\section{Limitations}

Several study limitations must be noted. First, the main measure of PTSD used for this analysis was not originally developed for use in Sierra Leone, and although we applied the recommended cut-off points to determine likely clinically significant levels of possible PTSD in this sample, these thresholds have not been validated in this population. Thus our assessments of change focused on examining PTSD as a continuous rather than a categorical variable, given that appropriate cut-off points for the population of Sierra Leone require further validation research.
We did not measure the amount of time since exposure, which is an important variable in understanding the nature of change in PTSD. However, in this sample, making such a determination is complicated by the chronic and complex nature of violence exposures in war, and ongoing stressors present in the postconflict environment. Similarly, the traumatic event reported by participants as their most distressing experience may have differed between assessment points. Because of translation and coding issues, it was not possible to determine whether PTSD symptoms at each time point related to the same event or different traumatic stresses.

Although our sample drew from more than five districts in Sierra Leone, it represents a cohort of children who were served by interim care centres or registered as eligible for services owing to their war involvement during a specified period. Thus our findings should not be generalised to the country overall nor are they a representative sample of former child soldiers. Ultimately child soldiers are a 'hidden' population and great logistical and ethical barriers exist in trying to determine a 'representative sample.. ${ }^{42}$ In addition, the longitudinal study was not designed to investigate the benefits of reintegration services as it was an observational study with risk of selection bias in sampling. The study design does not provide reliable evidence for the effectiveness of interim care centres. Accordingly, we chose not to include the care centre variable in the final model, to prevent potential misleading results about reintegration programmes. Evaluating the effectiveness of reintegration is an important area for future research requiring a different research design.

As all the measures here are self-reported, they are subject to over- and underreporting bias. For instance, fear of persecution might have led some young participants not to endorse questions about the perpetration of violence, whereas hopes of receiving additional services might have led others to overreport symptoms.

\section{Study implications}

Our study is the first to present longitudinal data on PTSD in one of the largest samples of male and female former child soldiers reported in the scientific literature to date and to shed light on the factors that shape change in symptoms over time. Our research emphasises the need to consider the type of violence experienced by former child soldiers, post-conflict stressors and 
the vital role of the child's social ecology in order to understand psychological outcomes. It is our hope that this and future research can raise awareness among local governments and the international community of the importance of investing in effective and sustainable responses to support the mental health needs of all war-affected youth, particularly those who manifest consistent or worsening patterns of post-traumatic stress symptoms, impairment and few protective resources. Despite the comparative resilience exhibited by a majority of the sample examined here, it must be noted that the overall rates of symptoms were still high when compared with other samples, and that this war-torn region continues to lack robust mental health services.

Systems for appropriate assessment, monitoring and follow-up for children most at risk for severe and persistent post-traumatic stress reactions should be envisaged from early on in the humanitarian response and can also provide a foundation for more sustainable systems of mental healthcare in the post-conflict environment. Increased efforts to establish culturally relevant, sustainable and responsive mental health services in countries where the lives of children and families are devastated by war remains a topic of pressing importance in global mental health research and advocacy.

\footnotetext{
Theresa S. Betancourt, SCD, MA, François-Xavier Bagnoud Center for Health and Human Rights, and Department of Global Health and Population, Harvard School of Public Health, Boston, USA; Elizabeth A. Newnham, MPsych, PhD, François-Xavie Public Health, Boston, USA; Elizabeth A. Newnham, MPsych, PhD, François-Xa
Bagnoud Center for Health and Human Rights, Harvard School of Public Health, Boston, USA, and School of Psychology, University of Western Australia, Perth, Australia; Ryan McBain, MSPH, François-Xavier Bagnoud Center for Health and Human Rights, and Department of Global Health and Population, Harvard School of Public Health, Boston, USA: Robert T. Brennan, EdM, MA, EdD, Francois-Xavier Bagnoud Center for Health and Humar A Boston, USA

Correspondence: Dr Theresa S. Betancourt, Department of Global Health and Population/François-Xavier Bagnoud Center for Health and Human Rights, Harvard School of Public Health, 651 Huntington Avenue, 7th floor, Boston, MA 02115, USA. Email: Theresa_Betancourt@harvard.edu
}

First received 17 Apr 2012, final revision 28 Feb 2013, accepted 27 Mar 2013

\section{Funding}

We acknowledge support from the US Institutes for Peace, the American Psychologica Foundation, the François-Xavier Bagnoud Center for Health and Human Rights, gran 1 K01MH07724601A2 from the National Institute of Mental Health, grant P60 MD00226 from the National Center for Minority Health and Disparities, and the Displaced Children's and Orphans' Fund of USAID, who helped to fund this work. E.A.N. was supported by Morgan Stanley Pediatrics Fellowship through the American Australian Association and an Early Career Fellowship through the National Health and Medical Research Council.

\section{Acknowledgements}

We are grateful to the local research assistants who conducted interviews in Sierra Leon and our field-based project coordinators as well as our colleagues at the Internationa Rescue Committee who collaborated in this data collection. In addition, we acknowledge Sidney Atwood and Ista Zahn who managed the data and supported the analyses. Above all, we thank our participants who have contributed to our growing understanding of traumatic stress and resilience in war-affected regions.

\section{References}

1 Betancourt TS, Brennan RT, Rubin-Smith J, Fitzmaurice GM, Gilman SE Sierr Leone's former child soldiers: a longitudinal study of risk, protective factors, and mental health. J Am Acad Child Adolesc Psychiatry 2010; 49: 606-15.

2 Derluyn I, Broekaert E, Schuyten G, De Temmerman E. Post-traumatic stress in former Ugandan child soldiers. Lancet 2004; 363: 861-3.

3 Kohrt BA, Jordans MJ, Tol WA, Speckman RA, Maharjan SM, Worthman CM et al. Comparison of mental health between former child soldiers and children never conscripted by armed groups in Nepal. JAMA 2008; 300: 691-702.
4 Betancourt TS. Attending to the mental health of war-affected children: the need for longitudinal and developmental research perspectives. J Am Acad Child Adolesc Psychiatry 2011; 50: 323-5.

5 Boothby N, Crawford J, Halperin J. Mozambique child soldier life outcome study: lessons learned in rehabilitation and reintegration efforts. Global Public Health 2006; 1: 87-107.

6 Betancourt TS, Newnham EA, Verdeli H, Borisova I, Neugebauer R, Bass J, et al. Moderators of treatment effectiveness for war-affected youth with depression in northern Uganda. J Adolesc Health 2012; 51: 544-50.

7 Ertl V, Pfeiffer A, Schauer E, Elbert T, Neuner F. Community-implemented trauma therapy for former child soldiers in northern Uganda: a randomized controlled trial. JAMA 2011; 306: 503-12.

8 Gregory J, Embrey DG. Reducing the effects of profound catastrophic trauma for former child soldiers: Companion Recovery model. Traumatology 2009; 15: $52-62$.

9 Fernando G, Miller K, Berger D. Growing pains: the impact of disaster-related and daily stressors on the mental health and psychosocial functioning of youth in Sri Lanka. Child Dev 2010; 81: 1192-210.

10 Betancourt TS, Agnew-Blais J, Gilman SE, Williams DR, Ellis BH. Past horrors, present struggles: the role of stigma in the association between war experiences and psychosocial adjustment among former child soldiers in Sierra Leone. Soc Sci Med 2010; 70: 17-26.

11 Annan J, Brier $M$. The risk of return: intimate partner violence in Northern Uganda's armed conflict. Soc Sci Med 2010; 70: 152-9.

12 Betancourt TS, Borisova II, Brennan RT, Williams TP, Whitfield TH, de la Soudiere M, et al. Sierra Leone's former child soldiers: a follow-up study of psychosocial adjustment and community reintegration. Child Dev 2010; 81: 1077-95.

13 World Health Organization. Process of Translation and Adaptation of Instruments. WHO, 2012 (http://www.who.int/substance_abuse/ research_tools/translation/en/index.html).

14 Macksoud MS, Aber JL. The war experiences and psychosocial development of children in Lebanon. Child Dev 1996; 67: 70-88.

15 Pynoos RS, Rodriguez N, Steinberg AS, Stauber M, Frederick C. UCLA PTSD Index for DSM-IV (Revision 1). UCLA Trauma Psychiatry Program, 1998.

16 Layne CM, Olsen JA, Baker A, Legerski JP, Isakson B, Pasalic A. Unpacking trauma exposure risk factors and differential pathways of influence: predicting post-war mental distress in Bosnian adolescents. Child Dev 2010; 81: 1053-76.

17 Steinberg A, Brymer MJ, Decker KB, Pynoos RS. The University of California at Los Angeles Posttraumatic Stress Disorder Reaction Index. Curr Psychiatry Rep 2004; 6: 96-100.

18 American Psychiatric Association. Diagnostic and Statistical Manual of Mental Disorders (4th edn, Text Revision) (DSM-IV-TR). APA, 2000.

19 MacMullin C, Loughry M. Investigating psychosocial adjustment of former child soldiers in Sierra Leone and Uganda. J Refugee Stud 2004; 17: 460-2.

20 Betancourt TS, Simmons S, Borisova I, Brewer SE, Iweala U, de la Soudiere M. High hopes, grim reality: reintegration and the education of former child soldiers in Sierra Leone. Compar Educ Rev 2008; 52: 565-87.

21 Bernstein DP, Fink L, Handelsman L, Foote J. Initial reliability and validity of a new retrospective measure of child abuse and neglect. Am J Psychiatry 1994; 151: 1132-6.

22 Williams DR, Yu Y, Jackson JS, Anderson NB. Racial differences in physical and mental health: socioeconomic status, stress, and discrimination. $J$ Health Psychol 1997; 2: 335-51.

23 United Nations Children's Fund. Sierra Leone: Multiple Indicator Cluster Survey 2005. UNICEF, 2007

24 Jacobson NS, Truax P. Clinical significance: a statistical approach to defining meaningful change in psychotherapy research. J Consult Clin Psychol 1991; 59: 12-9.

25 Newnham EA, Page AC. Bridging the gap between best evidence and best practice in mental health. Clin Psychol Rev 2010; 30: 127-42.

26 Raudenbush SW, Brennan RT, Barnett RC. A multivariate hierarchical model for studying psychological change within married couples. J Fam Psychol 1995; 9: 161-74

27 Barnett RC, Marshall NL, Raudenbush SW, Brennan R. Gender and the relationship between job experiences and psychological distress: a study of dual-earner couples. J Pers Soc Psychol 1993; 64: 794-806.

28 Goldberg AE, Smith JZ. Stigma, social context, and mental health: lesbian and gay couples across the transition to adoptive parenthood. J Counsel Psychol 2011; 58: 139-50.

29 Goldberg AE, Smith JZ. The social context of lesbian mothers' anxiety during early parenthood. Parenting Sci Pract 2008; 8: 213-39. 
30 Rubin DB. Multiple Imputation for Nonresponse in Surveys. Wiley, 1987.

31 Raudenbush SW, Bryk AS, Congdon RT. HLM 7: Hierarchical Linear and Nonlinear Modeling. Scientific Software International, 2011.

32 Betancourt TS, Khan KT. The mental health of children affected by armed conflict: protective processes and pathways to resilience. Int Rev Psychiatry 2008; 20: 317-28.

33 Tol WA, Jordans MJD, Kohrt BA, Betancourt TS, Komproe IH. Promoting mental health and psychosocial well-being in children affected by political violence: Part I - Current evidence for an ecological resilience approach. In Handbook of Resilience in Children of War (eds C Fernando, M Ferrari): 11-28. Springer, 2013.

34 Tol W, Jordans M, Kohrt B, Betancourt T, Komproe I. Promoting mental health and psychosocial well-being in children affected by political violence: Part II Expanding the evidence base. In Handbook of Resilience in Children of War (eds C Fernando, M Ferrari): 29-38. Springer, 2013.

35 Betancourt TS, Meyers-Ohki SE, Charrow AP, Tol WA. Interventions for children affected by war: an ecological perspective on psychosocial support and mental health care. Harv Rev Psychiatry 2013; 21: 70-91.

36 Klasen F, Oettingen G, Daniels J, Post M, Hoyer C, Adam H. Posttraumatic resilience in former Ugandan child soldiers. Child Dev 2010; 81: 1096-113.
37 Klasen F, Oettingen G, Daniels J, Adam H. Multiple trauma and mental health in former Ugandan child soldiers. J Trauma Stress 2010; 23: 573-81.

38 Durakovic-Belko E, Kulenovic A, Dapic R. Determinants of posttraumatic adjustment in adolescents from Sarajevo who experienced war. $J$ Clin Psychol 2003; 59: 27-40.

39 Bokszczanin A. PTSD symptoms in children and adolescents 28 months after a flood: age and gender differences. J Trauma Stress 2007; 20: 347-51.

40 Betancourt TS, Borisova I, de la Soudiere M, Williamson J. Sierra Leone's child soldiers: war exposures and mental health problems by gender. J Adolesc Health 2011;49: 21-8.

41 Araya M, Chotai J, Komproe IH, de Jong JT. Gender differences in traumatic life events, coping strategies, perceived social support and sociodemographics among postconflict displaced persons in Ethiopia. SOC Psychiatry Psychiatr Epidemiol 2007; 42: 307-15.

42 Betancourt TS, Borisova I, Williams TP, Meyers-Ohki SE, Rubin-Smith JE, Annan J, et al. Psychosocial adjustment and mental health in former child soldiers - systematic review of the literature and recommendations for future research. J Child Psychol Psychiatry 2013; 54: 17-36.

\section{poem}

\section{Conscious}

\section{A hospital poem by Wilfred Owen}

His fingers wake, and flutter up the bed. His eyes come open with a pull of will, Helped by the yellow may-flowers by his head. A blind-cord drawls across the window-sill . . . How smooth the floor of the ward is! what a rug! And who's that talking, somewhere out of sight? Why are they laughing? What's inside that jug? 'Nurse! Doctor!' 'Yes; all right, all right.' But sudden dusk bewilders all the air There seems no time to want a drink of water. Nurse looks so far away. And everywhere Music and roses burnt through crimson slaughter. Cold; cold; he's cold; and yet so hot:

And there's no light to see the voices by No time to dream, and ask - he knows not what.

Chosen by Alistair Stewart 